\title{
Increase of mitochondrial DNA in blood cells of patients with Leber's hereditary optic neuropathy with 11778 mutation
}

\author{
M-Y Yen, C-S Chen, A-G Wang, Y-H Wei,
}

See end of article for authors' affiliations

\section{Correspondence to:} May-Yung Yen, Department of Ophthalmology, Taipei Veterans General Hospital, Taipei 11217, Taiwan, Republic of China; myyen@vghtpe.gov.tw

Accepted for publication 9 April 2002

\begin{abstract}
Aims: To investigate the change of mitochondrial DNA (mtDNA) content in Leber's hereditary optic neuropathy (LHON) with 11778 mutation.

Methods: Mitochondrial DNA content in 27 LHON patients with 11778 mutation, 26 asymptomatic maternal relatives, and 23 normal controls was measured using a competitive polymerase chain reaction (PCR) method.

Results: The mean relative content of mtDNA (with respect to the $\beta$ actin gene) in LHON patients, asymptomatic maternal relatives, and normal controls was 245.5 (162.3), 238.2 (118.4), and 156.5 (61.6), respectively. There was a statistically significant difference between patients and controls and between relatives and controls. However, no statistically significant difference between patients and unaffected relatives was found. There was no statistically significant difference in the relative content of mtDNA between all males and females carrying 11778 mtDNA mutation

Conclusion: The results suggest that the increase in mtDNA content in LHON patients with 11778 mtDNA mutation may be due to a compensatory effect for respiratory chain defects of mitochondria. However, the increase of mtDNA content is the result rather than the cause of defective mtDNA. It still cannot explain the pathogenesis of LHON.
\end{abstract}

eber hereditary optic neuropathy (LHON) is a maternally transmitted disease and is characterised by acute or -subacute bilateral loss of central vision in young adults. ${ }^{1}$ It has been associated with 25 different mitochondrial DNA (mtDNA) mutations that were classified as primary and secondary mutations, according to their aetiological role in disease expression..$^{2-4}$ Although the primary aetiological factor of LHON is a mutation in the mitochondrial genome, the presence of a primary mtDNA mutation does not necessarily lead to visual loss. The optic neuropathy in LHON shows incomplete penetrance, and there are additional genetic and environmental aetiological factors, which are rather poorly defined, that influence the onset of the disease. ${ }^{56}$

Mitochondria are known to possess a second set of DNA that is structurally distinct from nuclear DNA. The mtDNA represents less than $1 \%$ of total cellular DNA. ${ }^{7}$ The number of mitochondria and the amount of mtDNA per cell are closely regulated within a given cell type but differ widely from cell type to cell type. ${ }^{8}$ The content of mtDNA has been found to increase with age..$^{9-11}$ It is thought that as the respiratory function of cells declines with age, the cells are able to compensate for reduced ATP synthesis by inducing the proliferation of mtDNA. ${ }^{11}$
Mitochondrial respiratory function was reported to be compromised in LHON patients. ${ }^{12-17}$ The mitochondrial dysfunction is thought to be caused by one or more mutations of mtDNA. However, the content of mtDNA of LHON patients has not been studied. It was our purpose to investigate whether the content of mtDNA is altered in LHON patients.

\section{MATERIALS AND METHODS}

Twenty seven patients ( 25 male and two female) with LHON with 11778 mutation, 26 asymptomatic maternal relatives (seven male and 19 female), and 23 normal controls ( 16 male and seven female) were included in this study (Table 1). The mean age at onset of LHON patients was 19.8 years, with a range of 8-38 years. At the time of blood sampling, the patients had lost vision for 2 months to 20 years. The mean age of LHON patients when their blood was sampled was 24 years, with a range of $11.5-40$ years. The mean age of asymptomatic maternal relatives was 33.8 years, with a range of 9-68 years. Both LHON patients and asymptomatic maternal relatives carry homoplasmic 11778 mutation of mtDNA. The mean age of normal controls was 35.3 years with a range of 5-83 years. They were tested negative for mtDNA 11778 mutation. They have no systemic disease as diabetes mellitus.

Table 1 Clinical data of LHON patients, asymptomatic maternal relatives, and normal controls

\begin{tabular}{llll}
\hline & LHON & Relatives & Controls \\
\hline Number & 27 & 26 & 23 \\
Sex ratio (M/F) & $25 / 2$ & $7 / 19$ & $16 / 7$ \\
Mean age (years) (SD) & $24.0(8.6)$ & $33.8(15.8)$ & $35.3(23.6)$ \\
$\quad$ Range & $11.5-40$ & $9-68$ & $5-83$ \\
Mean age of onset (years) (SD) & $19.8(8.8)$ & - & - \\
Mean duration of visual loss (years) & $5.1(7.8)$ & - & - \\
\hline
\end{tabular}


Table 2 The nucleotide sequence of six primers used in this study

\begin{tabular}{lll}
\hline Primers & Sequence $\left(5^{\prime}\right.$ to ${ }^{\prime}$ ) & Target DNA \\
\hline BA1 & CATGTGCAAGGCCGGCTTCG & nDNA, $\beta$ actin \\
BA2 & CTGGGTCATCTTCTCGCGGT & nDNA, $\beta$ actin \\
BA2-BA3 & CTGGGTCATCTTCTCGCGGTGCAGCACGGGGTGCTCCTC & nDNA, $\beta$ actin \\
L3540 & TCTCACCATCGCTCTTCTAC & mtDNA, ND1 \\
H3887 & TTGGTCTCTGCTAGTGTGGA & mDNA, ND1 \\
H3887-H3836 & TTGGTCTCTGCTAGTGTGGAGGCAGGAGTAATCAGAGGT & mtDNA, ND1 \\
\hline
\end{tabular}

The study was performed according to the tenets of the Declaration of Helsinki for research involving human subjects. With informed consent from each of the study subjects according to a protocol approved by the institutional review board of Taipei Veterans General Hospital, blood samples were obtained from LHON patients with the mtDNA 11778 $\beta \operatorname{actin}$ DNA
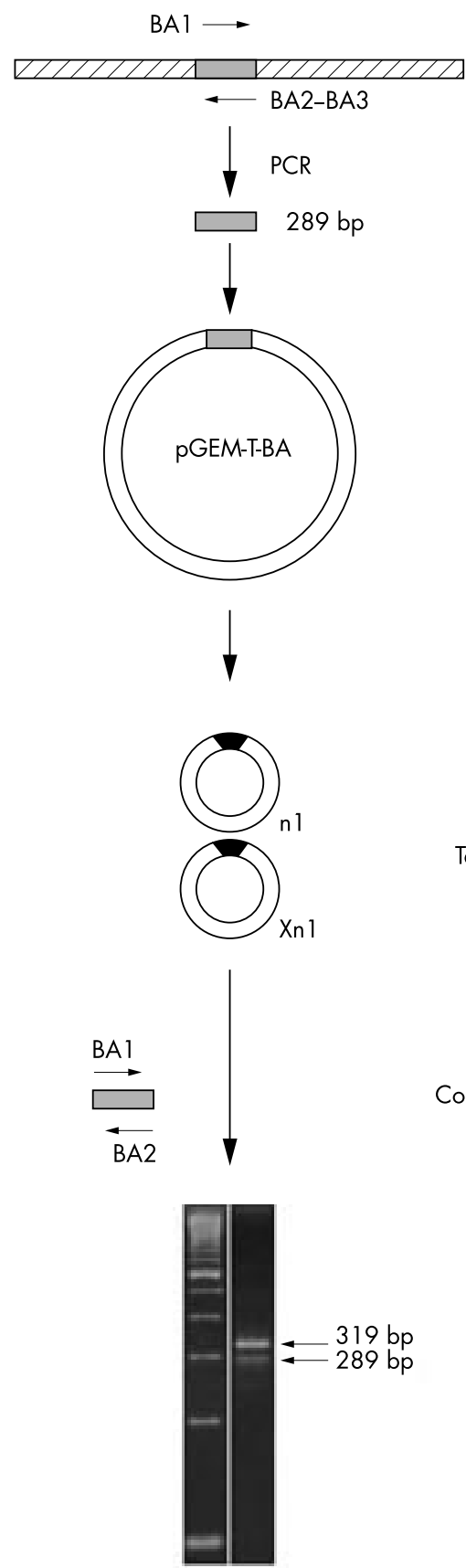

Mitochondrial DNA

$\mathrm{L} 3540 \longrightarrow$

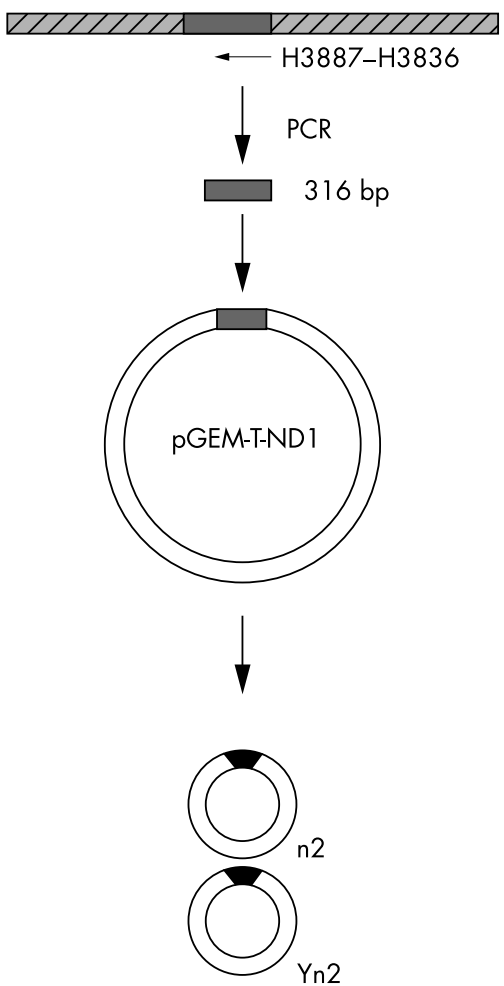

Concurrent PCR

Internal

standard

Target DNA
Figure 1 Summary of competitive polymerase chain reaction method used in this study. 
Table 3 Mean mtDNA content in LHON patients, asymptomatic relatives, and controls

\begin{tabular}{ll}
\hline Study subjects & Mean (SD) \\
\hline LHON patients $(n=27)$ & $245.5(162.3)^{*}$ \\
Asymptomatic relatives $(n=26)$ & $238.2(118.4) \dagger$ \\
Controls $(n=23)$ & $156.5(61.6)$ \\
\hline
\end{tabular}

*Patients $v$ controls, $\mathrm{p}<0.05$, Mann-Whitney test

tRelatives $v$ controls, $\mathrm{p}<0.05$, Mann-Whitney test.

Patients $v$ relatives, $p>0.05$, Mann-Whitney test.

mutation, their unaffected maternal relatives, and normal controls. Five $\mathrm{ml}$ of whole blood was withdrawn and stored in an EDTA containing glass tube.

Total DNA was extracted from the blood cells and purified using a DNA purification kit (Puregene, Gentra System, Inc, Minneapolis, MN, USA).

Using $\beta$ actin gene of nuclear DNA as an internal standard, the relative amount of mtDNA was determined by a competitive polymerase chain reaction (PCR) method modified from that developed by Gilliland et $a l^{18}$ and the competitor DNA was constructed by a method similar to that described by Celi et al. ${ }^{19}$ The nucleotide sequences of the primers used in this study are listed in Table 2. The whole procedure is summarised in Figure 1. To generate an internal DNA standard of $\beta$ actin gene, a plasmid was constructed by insertion of the PCR product amplified with primers BAI and BA2-BA3 to the pGEM-T vector (Promega Co, Madison, WI, USA). The internal DNA standard of $\beta$ actin gene was designed having a 30 base pair (bp) deletion. A volume of $0.5 \mu \mathrm{l}$ of the internal DNA standard $(5 \mu \mathrm{g} / \mu \mathrm{l})$ was introduced with DNA sample into the PCR mixture and was amplified with primers BAl and BA2. Two products with sizes of $319 \mathrm{bp}$ and $289 \mathrm{bp}$ were generated from the endogenous template and from the internal DNA standard, respectively. With the same approach, we generated an internal mtDNA NDl standard with another plasmid that was constructed by insertion of the PCR product amplified with primers L3540 and H3887-H3836 and cloned into the pGEM-T vector. The internal mtDNA NDl standard was designed to have a $31 \mathrm{bp}$ deletion. A volume of $0.5 \mu \mathrm{l}$ of the internal mtDNA standard $(3 \mathrm{mg} / \mathrm{\mu l}$ ) was introduced into the DNA sample and amplified with primers L3540 and H3887. Two products with sizes of $347 \mathrm{bp}$ and $316 \mathrm{bp}$ were then generated from the endogenous template and the internal NDl standard, respectively.

The competitive PCR was carried out for 30 cycles in a DNA thermal cycler (Model 2400, Perkin-Elmer/Cetus). Each aliquot of $50 \mu \mathrm{l}$ reaction mixture contained $200 \mu \mathrm{M}$ of each dNTP, 20 pmol of each primer, I unit of Taq DNA polymerase (Perkin-Elmer/Cetus, Norwalk, CT, USA), 50 mM KCI, $1.5 \mathrm{mM}$ $\mathrm{MgCl}_{2}$, and $10 \mathrm{mM}$ TRIS- $\mathrm{HCl}$ ( $\mathrm{pH} 8.3$ ). The thermal profile was as follows: denaturation at $94^{\circ} \mathrm{C}$ for 20 seconds, annealing at $58^{\circ} \mathrm{C}$ for 20 seconds, and extension at $72^{\circ} \mathrm{C}$ for 40 seconds. The PCR products were separated electrophoretically in 3\% agarose gel and stained with $1 \mu \mathrm{g} / \mathrm{ml}$ ethidium bromide at $25^{\circ} \mathrm{C}$ for 10 minutes. The intensities of the PCR products of the target and competitor DNA were analysed by digital scanning densitometry. A standard curve was constructed from a healthy person by plotting the competitor/target DNA intensity ratio against the logarithm of the content of the internal DNA standard added to the reaction mixture. Using the information derived from the best fit analysis of standard, the relative content of mtDNAs were normalised and calculated as an equivalent of one copy of $\beta$ actin gene.

Relative mtDNA content with respect to one copy of $\beta$ actin gene $=(($ intensity of 316 bp band/intensity of $347 \mathrm{bp}$ band $) \times$ (concentration of NDl internal standard))/( (intensity of 289 bp band/intensity of 319 bp band $) \times($ concentration of $\beta$ actin internal standard)).

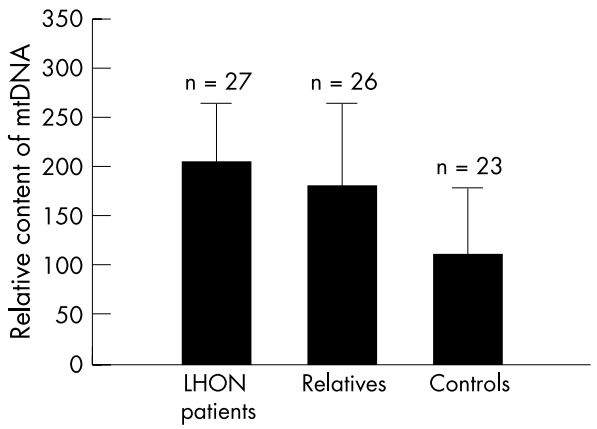

Figure 2 Comparison of the relative content of mtDNA in LHON patients, unaffected maternal relatives, and controls. The relative content of mtDNA in LHON patients (245.5 (162.3)) and unaffected maternal relatives $(238.2$ (1 1 18.4$))$ was higher than that of the controls (156.5 (61.6)) ( $p<0.05$, Mann-Whitney test). However, the relative content of m+DNA between LHON patients and unaffected maternal relatives has no statistically significant difference $(p>0.05$, Mann-Whitney test).

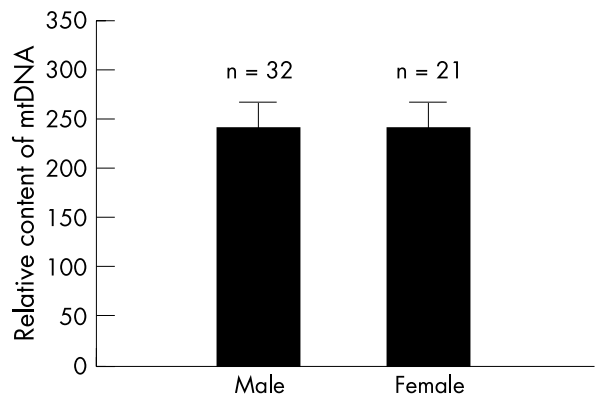

Figure 3 The relative content of mtDNA between all males $(242.4$ (26.7)) and female (241.2 (27.9)) carrying 11778 m+DNA mutation has no statistically significant difference ( $p>0.05$, Mann-Whitney test).

\section{RESULTS}

The mean relative content of mtDNA in blood cells of LHON patients with mtDNA 11778 mutation, in asymptomatic maternal relatives, and in normal controls was 245.5 (162.3), 238.2 (118.4), and 156.5 (61.6), respectively (Fig 2). There was a statistically significant difference in the relative content of mtDNA between the patients and normal controls and between relatives and normal controls (Mann-Whitney test, $\mathrm{p}<0.05)$. However, the difference between LHON patients and the asymptomatic maternal relatives did not reach statistical significance (Mann-Whitney test, p>0.05) (Table 3). The mean relative content of mtDNA in all males and females with 11778 mtDNA mutation no matter who was affected or unaffected was 242.4 (26.7) and 241.2 (27.9), respectively. The difference also did not reach statistical significance (MannWhitney test, $\mathrm{p}>0.05$ ). The content of mtDNA in LHON patients did not correlate with the age of onset or the duration from the onset of visual loss to the time of the blood test (Pearson correlation coefficient, $r<0.5, \mathrm{p}>0.05$ ).

\section{DISCUSSION}

The increase in content of mtDNA with age has been considered to be a compensatory response for the decline in respiratory function. ${ }^{1020}$ It is thought that as the respiratory function of tissue cells declines with age, the cells are mobilised to compensate for the reduced ATP synthesis by increasing the copy number of mtDNA. The energy deficit might be signalled to the nucleus, probably through a reactive oxygen species increase, ${ }^{21}{ }^{22}$ which can activate the expression of nuclear DNA encoded transacting factors able to induce 
mitochondrial proliferation..$^{23}$ Increased expression of mitochondrial transcription factor $\mathrm{A}$ and nuclear respiratory factor-1 were observed in aged human skeletal muscles. ${ }^{24}$ Over-proliferation of mitochondria and increased synthesis of mitochondrial respiratory enzymes were observed in a patient with mitochondrial myopathy. ${ }^{25}$ Increase in mitochondria and mtDNA was also found in human cells harbouring 4977 bp deleted mtDNA in response to oxidative stress. ${ }^{26}$

Although LHON is known as a mitochondrial disease, the molecular mechanism of the disease is unknown. Variable functional defects of complex $I$ in LHON have been reported. ${ }^{12-17}$ Brown et al ${ }^{27}$ reported an extensive biochemical analysis of the mitochondrial defects in lymphoblasts and trans-mitochondrial cybrids habouring LHON 3460, 11778 and 14484 mtDNA mutation. Respiration studies revealed that the maximal respiration rate reduced $20-28 \%, 30-36 \%$, and $10-15 \%$ in the cybrids with 3460,11778 , and 14484 mtDNA mutation, respectively. From this study, we found the content of mtDNA is increased in LHON patients and their asymptomatic maternal relatives harbouring 11778 mutation of mtDNA. However, the content of mtDNA did not correlate with the age of onset of the disease (Pearson correlation coefficient, $\mathrm{p}>0.05$ ). We believe that the change is a compensatory response for respiratory chain defects of mitochondria harbouring the 11778 mutation.

However, mtDNA content does not increase in all pathological conditions. The content of mtDNA was found to be decreased in adult, but not fetal, pancreatic islets of diabetic rats compared with non-diabetic rats. ${ }^{28}$ The content of mtDNA was found to be increased in light smokers, but decreased in heavy smokers. ${ }^{11}$ These findings suggest that under some conditions, other factors, such as diabetes or smoking, may modulate the compensatory mechanism in the control of mtDNA replication. In this study, we did not find a modulatory factor that affects the compensatory effect in LHON patients. The compensation does not fade with time because the increased content did not correlate with the duration from the onset of visual loss to the time when the patient was examined (Pearson correlation coefficient, $\mathrm{p}>0.05$ ).

Typical LHON is often seen in young males. The male to female ratio of affected individuals is about 4.2 to $1 .{ }^{6}$ Why males are predominantly affected is unknown. Our study did not show a statistically significant difference of mtDNA content between all males and females carrying 11778 mtDNA mutation.

The content of mtDNA between LHON patients and asymptomatic maternal relatives did not show a statistically significant difference. Both LHON patients and asymptomatic maternal relatives carried the mtDNA 11778 mutation. Since the ages of asymptomatic maternal relatives overlap with the LHON patients, some of them might develop LHON later. The increased mtDNA content in both groups cannot explain the pathogenesis of the onset of LHON.

\section{ACKNOWLEDGEMENT}

This work was supported by a grant to M-YY from the National Science Council (No NSC 89-2314-B-075-061), Taipei, Taiwan, Republic of China.

\section{Authors' affiliations}

M-Y Yen, C-S Chen, A-G Wang, Department of Ophthalmology, Taipei Veterans General Hospital, and the Department of Ophthalmology, National Yang-Ming University, Taipei 1 1217, Taiwan, Republic of China

Y-H Wei, Department of Biochemistry and Center for Cellular and Molecular Biology, National Yang-Ming University, Taipei 11217, Taiwan, Republic of China

\section{REFERENCES}

1 Newman $\mathbf{N}$. Leber hereditary optic neuropathy: new genetic consideration. Arch Neurol 1993;50:540-8.

2 Wallace DC, Brown MD, Lott MT. Mitochondrial DNA variation in human evolution and disease. Gene 1999;23:211-30.

3 Besch D, Wassinger B, Zrenner E, et al. A case of Leber optic neuropathy with a new point mutation in the cytochrome b gene. Ophthalmologe 2000;97:22-6.

4 Chinnery PF, Brown DT, Andrews RM, et al. The mitochondrial ND6 gene is a hot spot for mutations that cause Leber hereditary optic neuropathy. Brain 2001;124:209-18.

5 Johns DR. Genotype-specific phenotypes in Leber optic neuropathy. Clin Neurosci 1994;2:146-50.

6 Mackey DA, Oostra RJ, Rosenberg T, et al. Primary pathogenic mtDNA mutations in multigeneration pedigrees with Leber hereditary optic neuropathy. Am J Hum Genet 1996:59:481-5.

7 Lewin B. Gene expression 2. Eucaryotic chromosomes. 2nd ed. New York: John Wiley and Sons, 1980:590.

8 Robin ED, Wong R. Mitochondrial DNA molecules and virtual number of mitochondria per cell in mammalian cells. J Cell Physiol 1988:136:507-13.

9 Gadaleta MN, Rainaldi G, Lezza AMS, et al. Mitochondrial DNA copy number and mitochondrial DNA deletion in adult and senescent rats. Mutat Res 1992;275: 181-93.

10 Barrientos A, Casademont J, Cardellach F, et al. Reduced steady-state levels of mitochondrial RNA and increased mitochondrial DNA amount in human brain with aging. Mol Brain Res 1997;52:284-9.

11 Lee HC, Lu CY, Fahn HJ, et al. Aging- and smoking-associated alteration in the relative content of mitochondrial DNA in human lung. FEBS Lett 1998;441:292-6.

12 Majander A, Huoponen K, Savontaus ML, et al. Electron transfer properties of NADH:ubiquinone reductase in the NDI/3460 and ND4/ 11778 mutations of the Leber hereditary optic neuropathy(LHON) FEBS Lett 1991;292:289-92.

13 Degli Esposti $M$, Carelli V, Ghelli A, et al. Functional alterations of the mitochondrially encoded ND4 subunit associated with Leber hereditary optic neuropathy. FEBS Lett 1994;352:375-9.

14 Ghelli A, Degli Esposti M, Carelli V, et al. Changes in mitochondrial complex I activity and coenzyme $Q$ binding site in Leber hereditary optic neuropathy (LHON). Mol Aspects Med 1997;18(supp):S263-7.

15 Carelli V, Ghelli A, Bucchi L, et al. Biochemical features of mtDNA 14484 (ND6/M64V) point mutation associated with Leber hereditary optic neuropathy. Ann Neurol 1999;45:320-8.

16 Cock HR, Cooper JM, Schapira AHV. Functional consequences of the 3460-bp mitochodrial DNA mutation associated with Leber hereditary optic neuropathy. J Neurol Sci 1999;165:10-7.

17 Lodi R, Taylor DJ, Tabrizi SJ, et al. In vivo skeletal muscle mitochondrial function in Leber hereditary optic neuropathy assessed by ${ }^{31} \mathrm{P}$ magnetic resonance spectroscopy. Ann Neurol 1997:42:573-9.

18 Gilliland G, Perrin S, Blanchard K, et al. Analysis of cytokine mRNA and DNA: detection and quantitation by competitive polymerase chain reaction. Proc Natl Acad Sci USA 1990;87:2725-9.

19 Celi FS, Zenilman ME, Shuldiner AR. A rapid and versatile method to synthesize internal standards for competitive PCR. Nucleic Acids Res 1993;21:1047.

20 Pesce V, Cormio A, Fracasso F, et al. Age-related mitochondria genotypic and phenotypic alterations in human skeletal muscle. Free Radic Biol Med 2001;30:1223-33.

21 Mecocci P, Fano G, Fulle S, et al. Age-dependent increases in oxidative damage to DNA, lipid and proteins in human skeletal muscle. Free Radic Biol Med 1999;26:303-8

22 Pansarasa O, Bertorelli L, Vecchiet J, et al. Age dependent changes of antioxidant activities and markers of free radical damage in human skeletal muscle. Free Radic Biol Med 1999:27:617-22.

23 Li B, Holloszy JO, Semenkovish CF. Respiratory uncoupling induces $\delta$-aminolevulinate synthase expression through a nuclear respiratory factor-1-dependent mechanism in HeLa cells. J Biol Chem 1999:274:17534-40.

24 Lezza AM, Pesce V, Cormio A, et al. Increase expression of mitochondrial transcription factor $A$ and nuclear respiratory factor-1 in skeletal muscle from aged human subjects. FEBS Lett 2001;501:74-8.

25 Bakker HD, Scholte HR, van Den Bogert C, et al. Deficiency of the adenine nucleotide translocator in muscle of a patient with myopathy and lactic acidosis: a new mitochondrial defect. Pediatr Res 1993;33:412-7.

26 Wei YH, Lee CF, Lee HC, et al. Increases of mitochondrial mass and mitochondrial genome in association with enhanced oxidative stress in human cells harboring 4977 bp-deleted mitochondrial DNA. Ann NY Acad Sci 2001;928:97-112.

27 Brown MD, Trounce IA, Jun AS, et al. Functional analysis of lymphoblas and cybrid mitochondria containing the 3460,11778 , or 14484 Leber hereditary optic neuropathy mitochondrial DNA mutation. J Biol Chem 2000;275:39831-6.

28 Serradas $\mathbf{P}$, Giroix MH, Saulnier C, et al. Mitochondria deoxyribonucleic acid content is specifically decreased in adult, but not fetal pancreatic islets of the Goto-Kakizaki rat, a genetic model of noninsulin-dependent diabetes. Endocrinology 1995;136:5623-31. 